\title{
Consistency of the determinants of achieving fertility desires in Ghana: insights from 2003, 2008 and 2014 Ghana Demographic and Health Survey data sets
}

\author{
Isaac Yeboah ${ }^{1 *}\left(\mathbb{0}\right.$, Stephen Owusu Kwankye ${ }^{2}$ and Faustina Frempong-Ainguah ${ }^{2}$
}

*Correspondence:
isaac.yeboah@upsamail.
edu.gh
${ }^{1}$ Institute of Work,
Employment and Society,
University of Professional
Studies, Legon, P.O. Box LG
149 , Accra, Ghana
Full list of author information
is available at the end of the
article

*Correspondence:

.

${ }^{1}$ Institute of Work

Employment and Society,

149, Accra, Ghana

is available at the end of the article

\begin{abstract}
Sub-Saharan Africa has entered the early stage of the demographic transition with differences in and between countries. The relation between fertility preference and actual fertility is at the core of the demographic changes during the demographic transition in sub-Saharan Africa. At the current pace of the demographic transition, overachieved fertility (actual fertility being higher than fertility preference) is more prevalent in sub-Saharan Africa although some women do achieve their fertility preference. Our aim is to assess the trends and identify factors that consistently influence women with completed fertility to achieve their fertility desires in Ghana over a 10-year period. We used secondary data from the 2003, 2008 and 2014 Ghana Demographic and Health Surveys for the analysis. The sample size was restricted to currently married/living in union women aged $45-49$ years. The results indicate that underachieved fertility has increased from $25.1 \%$ in 2003 to $35.8 \%$ in 2014. Similarly, achieved fertility has also increased from $23.8 \%$ in 2003 to $26.0 \%$ in 2014 . On the contrary, overachieved fertility has decreased from $51.1 \%$ in 2003 to $38.2 \%$ in 2014. The most persistent determinants of achieved fertility relative to overachieved fertility in Ghana during the last three rounds of the Ghana Demographic and Health Surveys are child survival status, ethnicity and couple's fertility preference. The study provides support for programmatic interventions targeting improving child survival and regulating men's fertility preference.
\end{abstract}

Keywords: Fertility gap, Underachieved fertility, Overachieved fertility, Achieved fertility, Completed fertility

\section{Background}

Globally, fertility is declining but continues to stall in sub-Saharan Africa (Kebede et al., 2019; Schoumaker, 2019). The 2017 Ghana Maternal Health Survey (GMHS) reports that total fertility rate is 3.9 children per woman. Fertility preference of women has been identified as one of the key determinants of actual fertility (Bongaarts \& Casterline, 2012; Casterline, 2017; Cleland et al., 2020; Mbacké, 2017). The ability of individuals to make informed decisions on their sexual and reproductive rights is reinforced in global goals. The 2030 Agenda for Sustainable Development Goals (SDG) focuses on making

(c) The Author(s), 2021. Open Access This article is licensed under a Creative Commons Attribution 4.0 International License, which permits use, sharing, adaptation, distribution and reproduction in any medium or format, as long as you give appropriate credit to the original author(s) and the source, provide a link to the Creative Commons licence, and indicate if changes were made. The images or other third party material in this article are included in the article's Creative Commons licence, unless indicated otherwise in a credit line to the material. If material is not included in the article's Creative Commons licence and your intended use is not permitted by statutory regulation or exceeds the permitted use, you will need to obtain permission directly from the copyright holder. To view a copy of this licence, visit http:// creativecommons.org/licenses/by/4.0/. 
reproductive health and rights a specific aim as stated in SDG 5.6. As the report stated, 'the way forward is the full realization of reproductive rights, for every individual and couple by dismantling all the barriers whether economic, social or institutional that inhibit free and informed choice' (UNFPA, 2018; pg. 5).

Studies have established that fertility preference is not stable and changes due to prevailing circumstances (Liefbroer, 2009; Trinitapoli \& Yeatman, 2018). Furthermore, studies conducted in sub-Saharan Africa (SSA) including Ghana have identified a number of factors as predictors of high fertility preference (Ahinkorah et al., 2020; Kodzi et al., 2010; Odusina et al., 2020; Van Lith et al., 2013). Findings from these studies suggest positive relationship between fertility preference and actual fertility. Günther and Harttgen (2016) studying developing countries found that women in sub-Saharan Africa are unable to translate fertility preferences into actual fertility, and consequently leading to overachieved fertility. A woman's inability to achieve her fertility desire could result in two outcomes: underachieved or overachieved fertility. The situation where a woman's fertility preference is more than her actual fertility is termed as underachieved. On the other hand, if the fertility preference is lower than her actual fertility, it is described as overachieved fertility. The situation where a woman's preferred fertility is the same as her actual fertility is, however, termed as achieved fertility. Several factors account for the difference between a woman's preferred fertility and her actual fertility and the consistency of these factors in explaining this gap is the focus of this paper.

\section{Factors accounting for fertility gap}

The influence of childhood mortality on fertility behaviour could be explained from the insurance and replacement effect perspective. When childhood mortality is high, couples increase their target family size to ensure that their minimum number of preferred children survive into adulthood (Poppel et al., 2012; Reher et al., 2017). Regarding the replacement effect, studies have found that fertility behaviour could be a sequential decision-making model, where couples may work towards replacing a child who has just died (Gyimah \& Ferrnando, 2004; Wolpin, 1998). For instance, Gyimah and Fernando (2004) found that childhood mortality experience has long-term implications on fertility beyond short-term physiological effects in that the death of the first child in particular is associated with the risk of higher order births. We hypothesize that women who have had an experience of child loss are less likely to attain achieved fertility compared to overachieved fertility.

Partner characteristics have also been identified as important factors that predict fertility behaviour in sub-Saharan Africa. Fertility preference is much dependent on the social context. The outcome of a reproductive decision may depend on the social context that favours one reproductive choice or another (Voas, 2003). Within a patriarchal society, husbands have power in making reproductive decisions for their spouses. Therefore, the fertility preference of a man could determine the woman's actual fertility. In Ghana, a study by DeRose and Ezeh (2005) revealed that reproductive decision-making is determined by men's characteristics. Men with secondary and higher education were more likely to have a lower fertility preference compared with their counterparts with no education. In a similar study by Dodoo and Landewijk (1996), it was reported that women's desire to limit fertility is not associated with women having greater control 
over their reproductive decisions. Their study further revealed through a focus group discussion that the highly educated young women with high fertility preference are not able to achieve their preferred fertility without the approval of their husbands. However, other studies contend that the influence of men in taking reproductive decisions decreases with increasing years in marriage. Bankole (1995) argues that among the Yoruba in Nigeria, husbands take primary responsibility for fertility decisions at early stages of marriage, but their dominance reduces at the later stage of marriage when several children are born. In SSA, a couple's fertility preference is usually not the same (Muhoza et al., 2014). Having agreement on preferred fertility indicates spousal communication between the couple (Hinson, 2015; Kodzi et al., 2012). This could be that men in the sub-region are pronatalist and may have fertility preferences higher than women. Hence, women having more children than they preferred could be that their husbands preferred the extra number of children they had. Therefore, the study hypothesizes that women are more likely to attain achieved fertility when their partner's fertility preference is lower.

Female education assists in achieving planned number of births through the pathways of knowledge and access to contraception. Besides, women with female education are characterized with greater autonomy, reduced dependence on sons for social status and old age security (Dreze \& Murthi, 2001). Nitsche and Hayford (2020) in their study found that in the United States underachieved fertility is common among women with higher level of education. This is because most of the educated women delay their age of motherhood. Similarly, in a study using data from Demographic and Health Surveys (DHS) in 34 sub-Saharan African (SSA) countries, Kebede et al. (2021) found that desired family size declined with improvements in educational status of women. Hence, it is expected that higher educational level of women will reflect in the difference between women's fertility preference and actual fertility. Women with higher level of education are expected to attain achieved fertility.

Fertility differences of ethnic groups have been explained from different perspectives. First, it has been explained from the socioeconomic status perspective. For instance, women belonging to ethnic groups with high fertility are found to have low socioeconomic status (Akonor \& Biney, 2021; Gyimah, 2002a, 2002b). The other explanation is that cultural norms of ethnic groups regarding fertility may influence fertility. That is, women belonging to ethnic groups that place much value on higher number of children born are more likely to have high fertility. Hence, cultural norms of some ethnic groups encourage high fertility, especially, in sub-Saharan Africa.

The age group 45-49 years is typically a period when a woman is ending her reproductive life and fertility is low or virtually non-existent. For instance, in Ghana, age specific fertility rates per 1000 women for 3 years preceding the survey among women aged 45-49 years declined from 61 in 1988 to 16 in 2017 (Ghana Statistical Service et al., 2015; Ghana Statistical Service and Macro Inc., 1998). Nevertheless, some studies examining the relationship between a woman's preferred and actual fertility used a sample of women aged 15-49 years. This does not give a deeper understanding of the phenomenon, since fertility preference of a woman is subject to change especially at the early years of a woman's reproductive life. To date, there is very little research examining the relationship between a woman's preferred fertility and actual fertility using women aged 45-49 years (Canning et al., 2013; Carvalho et al., 2016; Casterline \& Han, 2017; 
Ibisomi et al., 2011). Comprehensive understanding of the relationship among women aged 45-49 is critical to advancement of knowledge about the demographic transition as observed in SSA including Ghana.

Studies have recorded that the pace of fertility decline in SSA is inconsistent with its rate of social and economic development (Bongaarts, 2017). This defies the conventional demographic transition theory. Rosero-Bixby and Casterline (1993) explained that fertility transitions are characterized by four main stages. These are pre-transition, onset of decline, mid-transition and post-transition levels of fertility. Agyei-Mensah (2006) has argued that Ghana is at the mid-transition stage characterized with slow or stalled fertility (Agyei-Mensah, 2006). According to Agyei-Mensah (2006) the attainment of fertility preference at this stage is very critical to fertility decline. One of the questions that remain unanswered by demographers is whether the difference between fertility preference and actual fertility at this stage of the transition could be one of the causes of stalling fertility in SSA.

With SSA characterized with overachieved fertility, the rising trend of underachieved and achieved fertility needs to be investigated to better understand the fertility behaviour of couples in sub-Saharan Africa (Channon \& Harper, 2019). While overachieved fertility has been associated with child loss, low education and rural places of residence, achieved fertility has been associated with partners' low fertility desire and differences in ethnicity (Channon \& Harper, 2019; Yeboah et al., 2021). Though the decline of overachieved fertility may be an indicator of fertility decline, a woman's ability to attain her fertility desire may not be a panacea to the slow pace of fertility transition in SSA. Rather, policy makers should be concerned with the nominal value of her fertility desires that was achieved.

There has been a plethora of studies to explain why most women in sub-Saharan Africa exceed their fertility preference. Little evidence, however, exists on the predictors of achieved and underachieved fertility. The purpose of this analysis is to assess the trends and identify consistent determinants of underachieved and achieved fertility relative to overachieved fertility in Ghana from 2003 to 2014 among women who have completed their fertility. The most consistent determinants will be identified to serve as intervention areas for the Ghana Health Service, the National Population Council of Ghana and other relevant partners to inform their programming activities towards further fertility reduction in Ghana.

Yeboah et al. (2021) have shown that women are unable to attain their fertility desires due to factors, such as marital experiences, child loss experience and unmet need for family planning. The paper investigated the predictors of fertility gap using pooled data sets from GDHS for over a period of 20 years and controlled for survey years. With this study, we aim to extend and deepen the discussion by Yeboah et al. (2021) by examining the changes and consistency in factors predicting the fertility gap over the 10-year period. In addition, within the 10-year period, Ghana has experienced a stall in fertility compared to the 20-year period used in the paper by Yeboah et al. (2021).

\section{Source of data and methods}

The data for analysis in this study consisted of women who were currently married or living/cohabiting with a partner in the 2003, 2008, and 2014 Ghana Demographic 
and Health Survey (GDHS) data set who were of age 45-49 years. These categories of women were selected for analysis, because they were asked questions concerning the fertility preference of their partners. The sample for analysis was also restricted to women with at least one live birth, who gave numeric responses to the question on ideal number of children and at the same time responded that they 'do not want more children' to the question on desire for more children. The study was restricted to women with at least one live birth, because the study controlled for child loss experience of these women. Besides, child mortality was computed using birth history of women in the study. Women with numeric responses were selected, because the inclusion of the non-numeric responses would have been difficult to determine how their actual fertility could differ from their fertility preference by quantification. The reason for including those who 'do not want more children' is because such women have been found to be usually less likely to have a child than those who want more children, especially in sub-Saharan Africa (Cleland et al., 2020). Those who were infecund or sterilized were excluded from the analysis, because infecundity is random concerning fertility preference (Casterline \& Han, 2017). The weighted sample sizes that were used for the analysis were: 304, 252 and 474, respectively, for 2003, 2008, and 2014.

\section{Study outcome variables}

The difference between fertility preference and actual fertility (fertility gap) was the outcome variable of this study. Fertility preference variable was derived from the ideal family size question in the DHS with emphasis on women who gave numeric responses. Actual fertility variable was derived from the number of children ever born question in the DHS. Women with ideal family size higher than actual fertility were recoded as having 'underachieved fertility', while those with ideal family size lower than actual fertility were recoded as having 'overachieved fertility'. Women with ideal family size as the same as actual fertility were, however, recoded as recording 'achieved fertility'. Hence, the difference between preferred and actual fertility yielded three results: underachieved, achieved and overachieved fertility.

\section{Predictor variables}

The following variables were selected based on the available literature and their relevance to the study: child loss experience, age at first birth, number of marital unions, ever use of modern contraceptives, educational attainment (in years), partner's education, couple's fertility preference, place of residence, religion and ethnicity. These variables were categorized as follows: child loss experience ['All survived,' 'one or more infant deaths', 'one or more child deaths' and 'both infant and child deaths'], couple's fertility preference ['Both want same', 'partner wants more,' 'partner wants fewer', and 'don't know'], age at first birth [under 18 years; $18-20$ years; and 21 years and above]; number of marital unions [once, and more than once]; ever-use of modern contraceptives [yes and no]; educational attainment [in years]; place of residence [urban and rural]; religion [Catholic; Other Christian; Islam; or Other] and ethnicity [Akan; Ga-Dangme; Ewe; Mole-Dagbani and Other]. 


\section{Statistical analysis}

Descriptive techniques of analysis including the use of percentages were used to describe the differences among the women by fertility gap. At the multivariate level, the multinomial logistic regression model was used to examine the net influence of possible individual socio-demographic and spousal characteristics on underachieved and achieved fertility compared to overachieved fertility among currently married women aged 45-49 years who have completed fertility. Women with overachieved fertility were used as the reference category, because it was assumed that most women in sub-Saharan Africa end their reproductive life by attaining overachieved fertility. This study, once again seeks to understand what factors consistently influence women to deviate from overachieved fertility to realize either underachieved or achieved fertility over the past 10 years. The model predicted underachieved and achieved fertility relative to overachieved fertility among women who have completed their fertility. Additional bivariate analysis was performed to explore differences in fertility behaviour and ethnic group affiliation of women. Thus, association between ethnic group and fertility behaviour (fertility preference and actual fertility) was tested using compare means and one-way analysis of variance.

\section{Results}

\section{Descriptive}

The total number of observations identified based on the variables of interest over the period was 1030. There was a steady decrease in the proportion of women who had an overachieved fertility between 2003 and 2014: 51.1 per cent in 2003, 44.2 per cent in 2008 and 38.2 per cent in 2014 (Fig. 1).

The proportion of women with underachieved fertility increased from 25.1 per cent in 2003 to 31.0 percent in 2008 and further increased to 35.8 per cent in 2014 (Fig. 1). On the other hand, achieved fertility increased from 23.8 per cent in 2003, 24.8 per cent in 2008 , and later increased to 26.0 per cent in 2014. The trend indicates that while the proportion of women with underachieved fertility increased between 2003 and 2014, proportion of women with achieved fertility increased during the same period. On the other hand, the proportion of women with overachieved fertility declined from 2003 to 2014 . The proportion of women with underachieved and achieved fertility were almost the

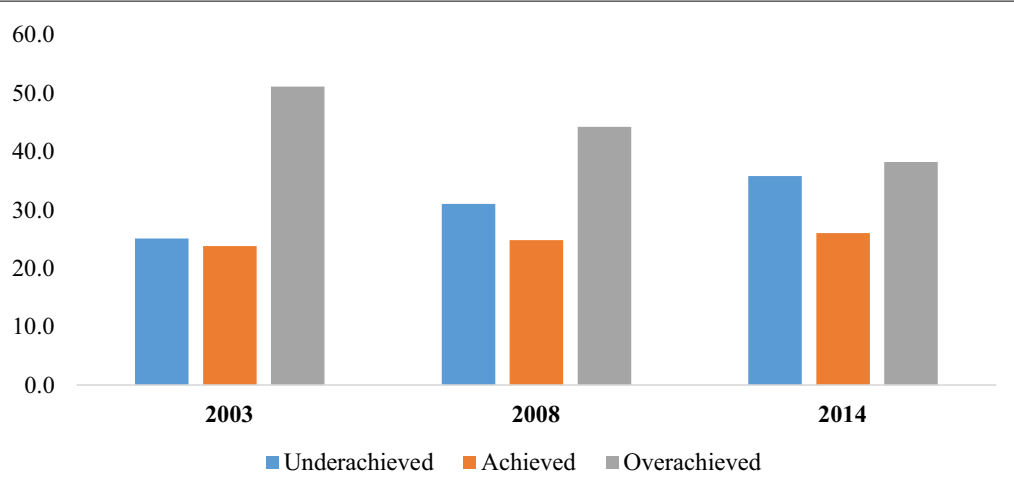

Fig. 1 Trends in fertility gap among women with completed fertility Source: Generated from the GDHS 2003, 2008 and 2014 
same in 2003. However, the difference between underachieved and achieved as observed in 2003 is different from what was observed in 2008 and 2014. The proportion of women with underachieved fertility increased much higher between 2008 and 2014, while the proportion of women with achieved fertility increased only slightly between 2008 and 2014.

Table 1 indicates that in all the three rounds of the surveys (2003-2014), a relatively higher proportion of women had all their children surviving the first 59 months after birth. There was a steady increase in the proportion of women who had all their children surviving child deaths between 2003 and 2014: 55.8 per cent in 2003, 57.2 per cent in 2008 and 61.6 per cent in 2014. Throughout the three survey periods, it is observed that the proportion of women who have ended their reproductive lives and residing in the urban areas was lower in 2008 compared to 2003 but much higher in 2014 (44.4\% in 2003; $42.3 \%$ in 2008 and $45.6 \%$ in 2014). In contrast, the proportion of women residing in rural areas in 2008 was higher than in 2003 and 2014. A higher proportion of respondents in the three survey years belonged to the Akan Ethnic Group relative to the other ethnic groups. About 7 in 10 women were Christians in all the three surveys (73.3\% in 2003; $74.0 \%$ in 2008 ; and $78.7 \%$ in 2014 ).

While the mean years of schooling have increased for respondents' partners, it has dropped for women from 5.4 years in 2003 to 4.6 years in 2014. The mean years of schooling of respondents' partners, on the other hand, was highest in 2008 (7.8 years) compared to 2003 (6.9 years) and 2014 (7.1 years).

The proportion of women who had their first birth at 18-20 years steadily decreased from 36.2 per cent in 2003 to 30.0 per cent in 2014. On the other hand, the proportion of women who had their first birth at 21 years and above decreased from 40.4 per cent in 2003 to 36.6 per cent in 2008 and increased to 41.2 per cent in 2014. Furthermore, in all the three surveys, more than half of the women have been in only one marital union, but this was highest in 2008. We also observe that the proportion of women who have ever used modern contraceptives was 42.2 per cent in 2003, rising to 44.8 per cent and 44.6 per cent, respectively, in 2014.

The proportion of couples who want same number of children as their spouses has consistently decreased between the three survey years. For instance, women with same fertility preference with partners declined from 49.6 per cent in 2003 to 42.1 per cent in 2014. Respondents who reported that their spouses/partners prefer more children also decreased from 20.1 per cent in 2003 to 17.7 per cent in 2008 and then increased to 25.8 per cent in 2014. Respondents who reported that their spouses prefer fewer children over the survey years were less than one-tenth of women interviewed in each survey year. The proportion of women who reported that they don't know their spouse's fertility preference increased from 24.4 per cent in 2003 to 32.1 per cent in 2008 and later declined to 24.5 per cent in 2014.

\section{Multivariate analysis}

Results of the multinomial logistic regression analysis for the three rounds of survey years are contained in Table 2. The significant predictors of underachieved and achieved fertility were child survival status, type of place of residence, ethnicity, age at first birth, ever use of modern contraceptives and couple's fertility preference. Three factors 
Table 1 Percentage distribution of women with completed fertility by socio-demographic characteristics

\begin{tabular}{|c|c|c|c|}
\hline Characteristics & $2003(n=304)$ & $2008(n=252)$ & $2014(n=474)$ \\
\hline \multicolumn{4}{|l|}{ Child loss experience } \\
\hline All children alive & 55.8 & 57.2 & 61.6 \\
\hline One or more infant deaths & 22.0 & 20.9 & 19.2 \\
\hline One or more child deaths & 14.2 & 13.4 & 12.1 \\
\hline Both infant and child deaths & 8.1 & 8.5 & 7.1 \\
\hline \multicolumn{4}{|l|}{ Place of residence } \\
\hline Urban & 44.4 & 42.3 & 45.6 \\
\hline Rural & 55.6 & 57.7 & 54.4 \\
\hline \multicolumn{4}{|l|}{ Ethnicity } \\
\hline Akan & 50.9 & 51.3 & 52.3 \\
\hline Ga-Dangbe/Ewe & 21.6 & 20.1 & 20.3 \\
\hline Mole-Dagbani & 10.7 & 15.9 & 14.9 \\
\hline Other & 16.8 & 12.7 & 12.5 \\
\hline \multicolumn{4}{|l|}{ Religion } \\
\hline Catholic & 15.1 & 14.1 & 10.2 \\
\hline Other Christians & 58.2 & 59.9 & 68.5 \\
\hline Islam & 15.6 & 12.7 & 14.9 \\
\hline Other & 11.0 & 13.4 & 6.4 \\
\hline \multicolumn{4}{|l|}{ Education (in completed years) } \\
\hline Range & $0.0-22.0$ & $0.0-17.0$ & $0.0-17.0$ \\
\hline Mean (SD) & $5.4(5.5)$ & $5.1(5.0)$ & $4.6(5.4)$ \\
\hline \multicolumn{4}{|l|}{ Age at first birth } \\
\hline$<18$ years & 23.4 & 28.9 & 28.8 \\
\hline $18-20$ years & 36.2 & 34.6 & 30.0 \\
\hline 21 years above & 40.4 & 36.6 & 41.2 \\
\hline \multicolumn{4}{|l|}{ Number of marital unions } \\
\hline Once & 60.7 & 67.7 & 61.6 \\
\hline Two or more unions & 39.3 & 32.3 & 38.4 \\
\hline \multicolumn{4}{|c|}{ Ever use of modern contraceptive } \\
\hline Yes & 42.2 & 44.8 & 44.6 \\
\hline No & 57.8 & 55.2 & 56.4 \\
\hline \multicolumn{4}{|c|}{ Partner's education (in completed years) } \\
\hline Range & $0.0-25.0$ & $0.0-18.0$ & $0.0-18.0$ \\
\hline Mean (SD) & $6.9(6.7)$ & $7.8(5.3)$ & $7.1(5.4)$ \\
\hline \multicolumn{4}{|l|}{ Partner's preferred fertility } \\
\hline Both want same & 49.6 & 43.3 & 42.1 \\
\hline Husband wants more & 20.1 & 17.7 & 25.8 \\
\hline Husband wants fewer & 6.0 & 6.9 & 7.5 \\
\hline Don't know & 24.4 & 32.1 & 24.5 \\
\hline
\end{tabular}

Source: Generated from the GDHS 2003, 2008 and 2014

consistently predicted underachieved and achieved fertility throughout the three rounds of survey. These are child survival status, ethnicity and couple's fertility preference.

Factors observed as not significantly associated with underachieved and achieved fertility include education of the woman, religion, number of marital unions and partner's education. The results show that child survival status is significantly associated 
Table 2 Results of multinomial logistic regression of fertility gap in Ghana

\begin{tabular}{|c|c|c|c|c|c|c|}
\hline & \multicolumn{2}{|l|}{2003} & \multicolumn{2}{|l|}{2008} & \multicolumn{2}{|l|}{2014} \\
\hline & UF vs OF & AF vs OF & UF vs OF & AF vs OF & UF vs OF & AF vs OF \\
\hline & RRR (S.E) & RRR (S.E) & RRR (S.E) & RRR (S.E) & RRR (S.E) & RRR (S.E) \\
\hline \multicolumn{7}{|c|}{ Survival status (ref = All children survived) } \\
\hline Infant deaths & $0.50(0.19)$ & $0.31(0.14)^{*}$ & $0.55(0.23)$ & $0.19(0.10)^{* *}$ & $0.58(0.17)$ & $0.47(0.15)^{*}$ \\
\hline Child deaths & $0.19(0.91)^{* *}$ & $0.38(0.17)^{*}$ & $0.98(0.49)$ & $0.52(0.29)$ & $0.75(0.26)$ & $0.83(0.31)$ \\
\hline Infant and child deaths & $0.16(0.11)^{* *}$ & $0.41(0.25)$ & $0.74(0.44)$ & $0.49(0.31)$ & $0.16(0.11)^{* *}$ & $0.66(0.31)$ \\
\hline \multicolumn{7}{|c|}{ Type of place of residence (ref = Urban) } \\
\hline Rural & $1.01(0.39)$ & $0.37(0.15)^{*}$ & $1.13(0.44)$ & $1.45(0.59)$ & $0.60(0.16)$ & $0.74(0.21)$ \\
\hline $\begin{array}{l}\text { Education (in completed } \\
\text { years) }\end{array}$ & $1.05(0.04)$ & $1.01(0.04)$ & $1.00(0.045)$ & $1.01(0.05)$ & $1.05(0.04)$ & $1.05(0.04)$ \\
\hline \multicolumn{7}{|l|}{ Ethnicity (ref=Akan) } \\
\hline Ga-Dangbe/Ewe & $0.89(0.38)$ & $0.96(0.41)$ & $1.12(0.53)$ & $0.89(0.45)$ & $1.06(0.37)$ & $0.95(0.33)$ \\
\hline Mole-Dagbani & $3.33(1.78)^{*}$ & $3.61(1.97)^{*}$ & $3.74(2.24)^{*}$ & $5.47(1.58)^{* *}$ & $1.52(0.62)$ & $0.64(0.27)$ \\
\hline Other & $2.02(1.09)$ & $2.36(1.28)$ & $2.64(1.57)$ & $2.49(1.65)$ & $3.10(1.29)^{* *}$ & $1.07(0.47)$ \\
\hline \multicolumn{7}{|l|}{ Religion (ref=Catholic) } \\
\hline Other Christian & $1.40(0.65)$ & $1.08(0.52)$ & $0.71(0.36)$ & $1.49(0.82)$ & $0.90(0.32)$ & $0.86(0.32)$ \\
\hline Islam & $1.01(0.62)$ & $0.47(0.29)$ & $1.08(0.67)$ & $0.94(0.69)$ & $1.39(0.58)$ & $0.89(0.42)$ \\
\hline Other & $1.34(0.80)$ & $1.12(0.66)$ & $1.08(0.66)$ & $0.99(0.69)$ & $0.86(0.46)$ & $1.04(0.56)$ \\
\hline \multicolumn{7}{|l|}{ Age at first birth (ref $\leq 18$ years) } \\
\hline $18-20$ years & $0.93(0.41)$ & $1.33(0.61)$ & $0.40(0.17)^{*}$ & $0.86(0.39)$ & $1.66(0.52)$ & $1.47(0.48)$ \\
\hline 21 years + & $2.54(1.11)^{*}$ & $3.35(1.53)^{* *}$ & $1.14(0.46)$ & $1.24(0.58)$ & $1.79(0.54)$ & $1.43(0.46)$ \\
\hline \multicolumn{7}{|c|}{ Number of marital union (ref=Once) } \\
\hline More than once & $0.93(0.31)$ & $0.62(0.22)$ & $0.96(0.36)$ & $0.62(0.26)$ & $1.23(0.32)$ & $0.64(0.18)$ \\
\hline \multicolumn{7}{|c|}{ Ever use of modern contraceptives $(r e f=\mathrm{No})$} \\
\hline Yes & $0.58(0.19)$ & $0.48(0.17)^{*}$ & $0.69(0.25)$ & $1.08(0.41)$ & $0.68(0.16)$ & $0.68(0.17)$ \\
\hline $\begin{array}{l}\text { Partner's education (in com- } \\
\text { pleted years) }\end{array}$ & $0.97(0.03)$ & $0.97(0.03)$ & $1.00(0.05)$ & $1.04(0.05)$ & $0.98(0.03)$ & $0.94(0.03)$ \\
\hline \multicolumn{7}{|c|}{ Couple's fertility preference (ref = Both want same) } \\
\hline Partner wants more & $0.79(0.31)$ & $0.88(0.35)$ & $0.64(0.290$ & $0.39(0.19)$ & $0.51(0.15)^{*}$ & $0.42(0.13)^{* *}$ \\
\hline Partner wants fewer & $1.82(1.25)$ & $2.45(1.69)^{*}$ & $5.44(2.05)^{*}$ & $1.44(1.22)$ & $4.56(2.37)^{* *}$ & $1.03(0.64)$ \\
\hline Don't know & $0.95(0.42)$ & $1.18(0.52)$ & $0.79(0.32)$ & $0.32(0.15)^{* *}$ & $0.96(0.29)$ & $0.69(0.23)$ \\
\hline Sample size & 304 & & 252 & & 474 & \\
\hline Log likelihood & -274.17 & & -230.81 & & -469.66 & \\
\hline Prob $>\mathrm{Chi}^{2}$ & 0.0004 & & 0.0067 & & 0.0000 & \\
\hline
\end{tabular}

Source: Generated from the GDHS 2003, 2008 and 2014; ${ }^{*} p<0.05 ;{ }^{* *} p<0.01 ;{ }^{* * *} p<0.001$

UF underachieved fertility, OF overachieved fertility, $A F$ achieved fertility, RRR relative risk ratio, $S E$ standard error

with achieved fertility throughout the three rounds of surveys. Using the 2003 data, women who have experienced infant deaths were $69 \%$ less likely to attain achieved fertility compared to those who had all children surviving child deaths.

Using the 2014 data, women who have experienced both infant and child deaths were $53 \%$ less likely to attain achieved fertility compared to those who had all children surviving child deaths. Child survival status is also significantly associated with underachieved fertility in 2003 and 2014. Using the 2014 data, women who have 


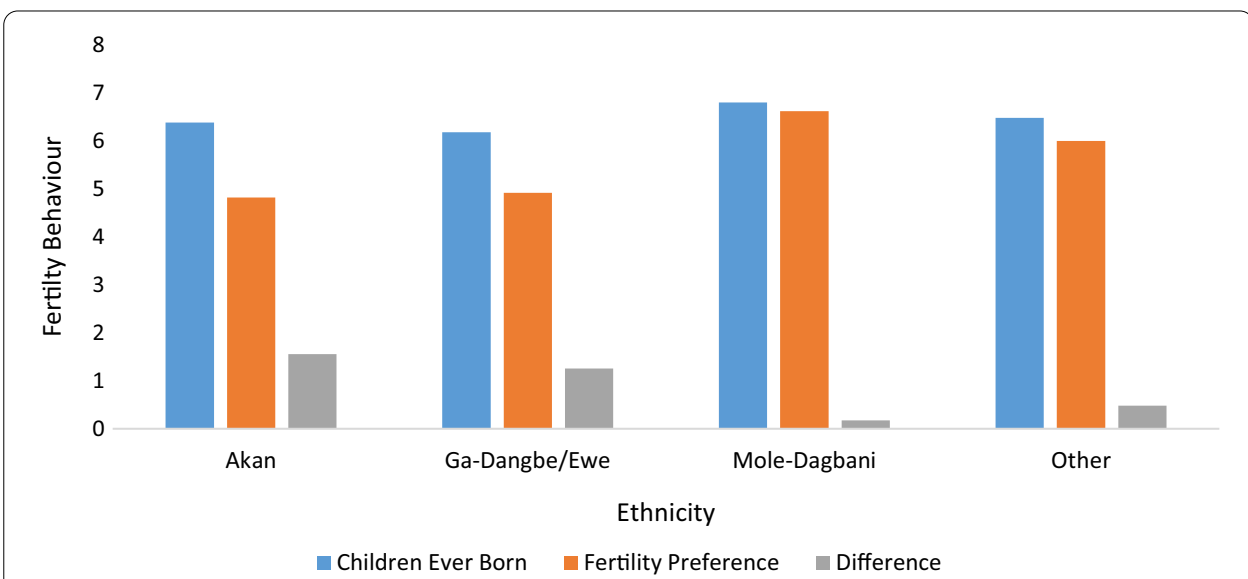

Fig. 2 Association between ethnicity and fertility behaviour (fertility preference and actual fertility) in Ghana, 2003 GDHS Source: Generated from the GDHS 2003

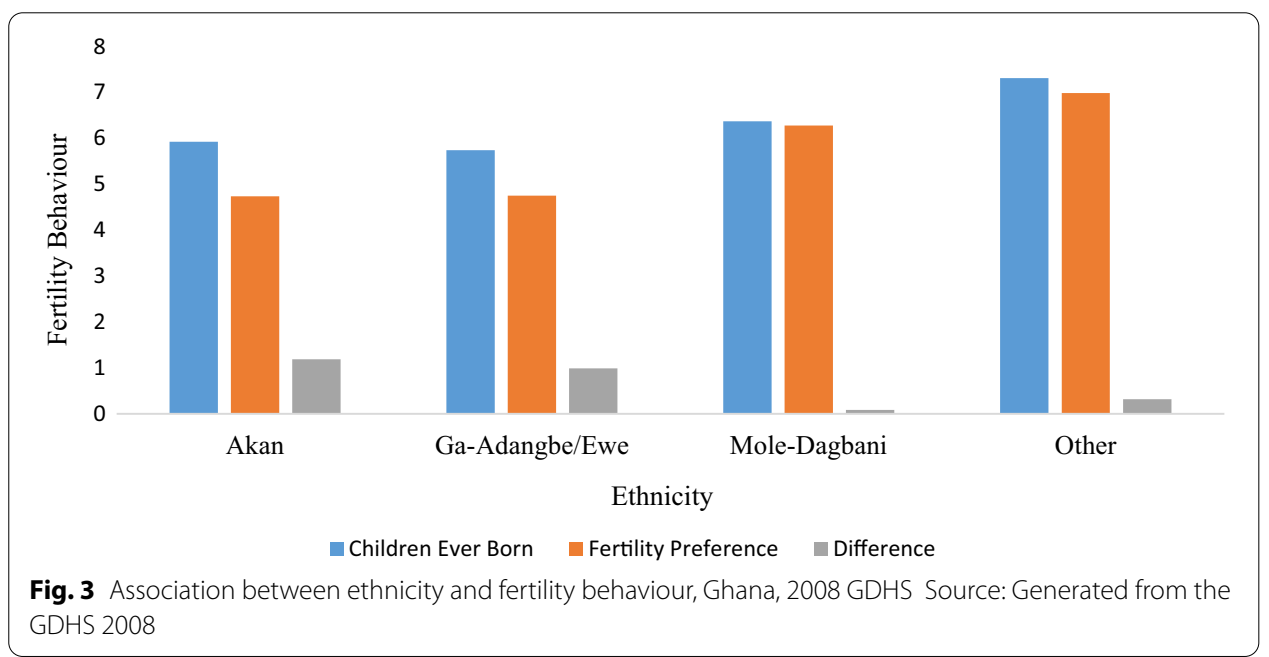

experienced both infant and child deaths were $84 \%$ less likely to attain underachieved fertility (RRR: 0.16: $p<0.05$ ).

Type of place of residence is significantly associated with achieved fertility only in 2003 (RRR: $0.37 ; p<0.05$ ). Women who reside in rural areas were $63 \%$ less likely to attain achieved fertility compared to those in urban areas.

Using the 2003 data, women belonging to the Mole-Dagbani Ethnic Group were 3.33 times as likely to attain underachieved fertility compared to the Akan women. In 2008, Mole-Dagbani women recorded an increase in the relative risk ratio of attaining underachieved fertility compared to what was recorded in 2003 (RRR: 3.74; $p<0.05$ ). Similarly, in 2008, Mole-Dagbani women recorded an increase in the risk ratio of achieved fertility compared to what was recorded in the immediate past survey (2003), observing 3.61 and 5.47 times as likely to attain achieved fertility, respectively, in 2003 and 2008. Using the data in 2014, women belonging to the Other ethnic group were 3.10 times as likely to attain underachieved fertility compared to Akan women. Further analysis revealed that Mole-Dagbani women 


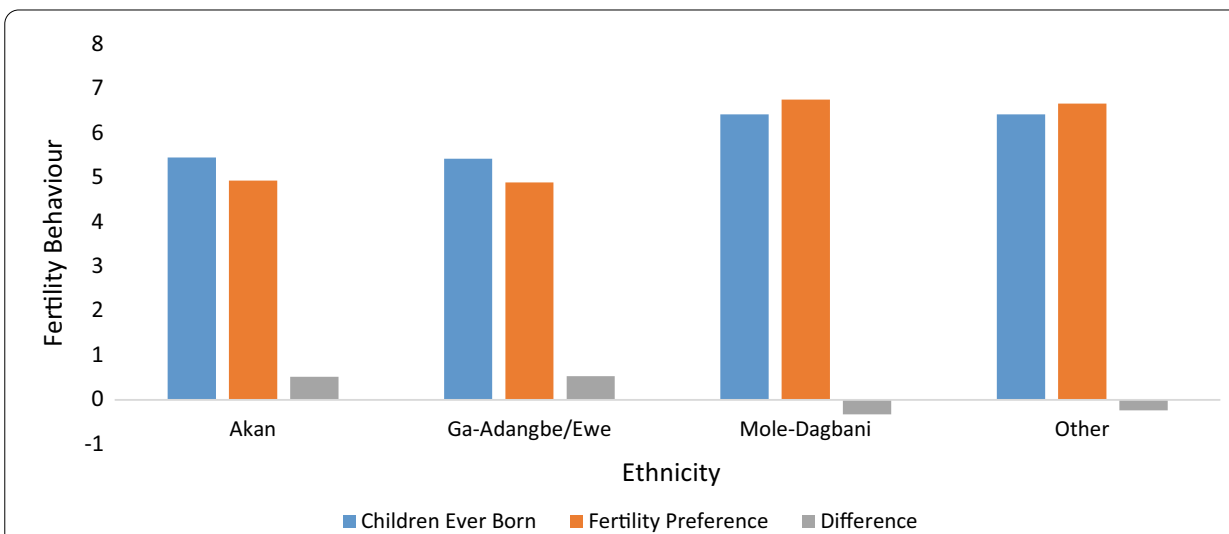

Fig. 4 Association between ethnicity and fertility behaviour in Ghana, 2014 GDHS Source: Generated from the GDHS 2014

had higher mean of fertility preference and higher mean of actual fertility across the three rounds of survey (Figs. 2, 3, 4). In addition, Mole-Dagbani women had the least difference between children ever born and fertility preference. For instance, the difference between children ever born and fertility preference was $0.18,0.09$ and -0.33 in 2003, 2008 and 2014, respectively.

Age at first birth is significantly associated with underachieved fertility. In 2003, women who had first birth at the age of 21 years and above were 2.54 times as likely to attain underachieved fertility compared to those whose age at first birth was less than 18 years (Table 2). In 2008, women who had first birth at the age 18-20 years were $60 \%$ less likely to attain underachieved fertility compared to those who had first birth when less than 18 years (RRR: $0.40 ; p<0.05$ ). Using 2003 data, women who had first birth when 21 years and above were 3.35 times as likely to attain achieved fertility (RRR: $3.35 ; p<0.01$ ). Ever use of modern contraceptives is significantly associated with achieved fertility with relative risk ratio (RRR) for 2003 of 0.48 and $p<0.05$.

Couple's fertility preference was found to be associated with achieved fertility in 2003, 2008 and 2014 (Table 2). Using the 2003 data, women whose partners want fewer children were more likely to attain achieved fertility compared to those who have same fertility preference with their partners (RRR: $2.45 ; p<0.05$ ). In 2008, women who don't know the fertility preference of their partners were $68 \%$ less likely to attain achieved fertility compared to those who have same fertility preference with their partners (RRR: $0.32 ; p<0.01$ ). Using the 2014 data, women with partners who want more children were $48 \%$ less likely to attain achieved fertility compared to those who have same fertility preference with their partners (RRR: $0.42 ; p<0.01$ ). The results also indicate that couple's fertility was significantly associated with underachieved fertility in 2008 and 2014. Using the 2008 data, women with partners who want fewer children were 5.44 times as likely to attain underachieved fertility compared to those who have same fertility preference with their partners (RRR: 5.44; $p<0.05)$. Finally, using the 2014 data, women with partners who want more children were $49 \%$ less likely to attain underachieved fertility compared to those who have same fertility preference with partner (RRR; $0.51 ; p<0.05$ ). On the other hand, women whose partners want fewer children were 4.56 times as likely to attain 
underachieved fertility compared to those who have same fertility preference with partners (RRR: $4.56 ; p<0.01)$.

\section{Discussion}

The aim of this paper was to examine the trends and identify consistent determinants of fertility gap across the latest three rounds of the Ghana Demographic and Health Survey (GDHS) in the past 10 years. The discussion of this study is situated with the demographic transition, where Ghana's fertility is classified as one that is stalling. In all the three surveys, a relatively higher proportion of women with completed fertility had overachieved fertility by the end of their reproductive lives. This finding is consistent with studies by Muhoza et al. (2014) who revealed that a higher proportion of women in East African countries have overachieved fertility. Nevertheless, the results of this analysis revealed a wide gap observed between women with overachieved fertility and achieved fertility in 2003 and that was gradually closed in 2014. This result could be associated with the increasing proportion of women with all children surviving between 2003 and 2014 (55.8\% in 2003 to $61.6 \%$ in 2014 presented in Fig. 1). The increasing proportion of women with underachieved fertility could be due to the increasing low fertility preference of women's partners. Yeboah et al (2021) have earlier reported that women are more likely to attain underachieved fertility when their partner's fertility preference is lower. The increasing proportion of women with improvement in child survival may be attributed to maternal and child health policies and intervention programmes by the government and NGOs (Kayode et al., 2016). This consequently led to improvement in health care infrastructure, reduced inequality in healthcare uptake, eased financial challenge of healthcare service and drew government attention to meeting the MDG and SDG goals. It is, therefore, expected that changes in childhood mortality will most likely affect the fertility gap of women in Ghana. In addition, it is more likely that overachieved fertility will further decline, since there is the higher possibility of children surviving child deaths (Wencak, 2013).

The increase in the proportion of women whose age at first birth is less than 18 years between 2003 and 2014 implies that teenage pregnancy and motherhood were a substantial social and health issue in Ghana with implications on the health of the mother and child. A general observation is that throughout the three survey years, a relatively higher proportion of the respondents have never used modern contraceptives as birth control methods in Ghana.

It was observed that over the years, women's partners had higher mean years of school. This is comparatively higher than women's mean years of schooling. This corroborates other studies that indicate that despite improvement in education, inequality exists between men and women's education in Ghana (Aziato, 2016). The higher proportion of respondents with partners who had same fertility preference suggests the relevance of the study of fertility gap in sub-Saharan Africa, where reproductive decision making to a larger extent is determined by the man (DeRose \& Ezeh, 2005; Isiugo-Abanihe, 1994).

The results of the multivariate analysis revealed that child survival status consistently predicted fertility gap among women who have ended their reproductive ages in Ghana. Childhood mortality in the form of either infant or child deaths reduced the likelihood of achieved or underachieved fertility across the three survey years. This result suggests 
that child loss by a mother has an important impact on her decision to continue having additional children over the past decade in Ghana. It is also possible that with the experience of child deaths, couples may increase their preferred family size to ensure a minimum number of children surviving to reach adulthood (Reher et al., 2017). Another fertility response to child loss is when couples through the hoarding effect decide to have more children than they prefer as insurance against future child loss (Feyisetan \& Casterline, 2000; Gyimah \& Fernando, 2004). This consequently leads to overachieved fertility.

Studies have recorded differences in rural-urban healthcare systems across different geographical regions with implications on fertility behaviour, contraceptive use and child health outcome (Amu \& Sekyi, 2018). In 2003, women residing in rural areas were less likely to attain achieved fertility compared to those in urban centres. This finding is in line with a study by Van de Poel et al. (2009), where women living in rural areas were characterized by lack of electricity, safe water deprivation, lack of amenities and poor accessibility to healthcare centres.

Regarding ethnicity, Mole-Dagbani women belong to the patrilineal society mostly located in Northern Ghana, while the Akan belong to the matrilineal society. The findings suggest that women belonging to patrilineal societies were significantly more likely to have achieved fertility compared to those belonging to matrilineal lineage. Further analysis also suggested that the Mole-Dagbani women had higher fertility preference and higher actual fertility, thereby narrowing the fertility gap among them. The finding from this study is consistent with what some studies have shown in Ghana (Akonor \& Biney, 2021; Gyimah, 2002a, 2002b). A study by Akonor and Biney (2021) have shown that Mole-Dagbani women (mostly located in the northern part of Ghana) and those from the Other Ethnic Group (predominantly northern ethnic groups) have both higher fertility preferences and actual fertility than those belonging to the Akan Ethnic Group who are largely found in the southern part of Ghana. A plausible explanation could be that women belonging to the Mole-Dagbani Ethnic Group are characterized by relatively lower levels of education that are important considerations in fertility decisions at the household level. In addition, this may be explained by contextual social norms which deserve further exploration.

Using the data in 2003, women who had first birth at age 21 and above were more likely to attain achieved fertility compared to those who had first birth before 18 years. They were also more likely to attain underachieved fertility. This means that women who delayed first birth were significantly more likely to have achieved fertility. Research has shown that the likelihood of underachieved fertility is higher at later age of first birth (Ibisomi et al., 2011). This may be, because early age at first birth prolongs the reproductive life of women and exposes women to high fertility especially in socio-cultural environments, where contraceptive use is low. In contrast, later age at first birth shortens the reproductive years of women, which in turn, could reduce their fertility. Besides, too early or too late childbearing could have negative reproductive health implications, which women who deliberately decide to postpone childbearing are very much aware of.

The results for the use of birth control methods were contrary to expectation. Using the 2003 data, the results indicate that women who have ever used modern contraceptives were less likely to attain achieved fertility. It is possible that women with child loss 
experience may be more among this category who have never used modern contraceptives. It may also be plausible to speculate women who had ever used modern contraceptives used them to space their high preferred number of births than to limit births.

One other striking finding from the multivariate analysis was about the couple's preferred fertility. Couple's fertility preference was one of the three significant predictors of underachieved and achieved fertility across all the rounds of surveys. This finding suggests that men's dominance over reproductive decisions at the household level is vital in reducing fertility preference and actual fertility (Caldwell \& Caldwell, 1987; Dodoo, 1994; Dodoo \& Landewijk, 1996).

\section{Limitations and strengths of study}

The main limitation is that the survey question on fertility preference derived from the desired family size question is prone to the challenge of ex-post rationalization. This is because respondents may not include possible child deaths in their ideal family size. In addition, preferred fertility is influenced by individual and household circumstances at the time of the survey. This could lead to respondents upwardly giving biased responses. Childhood mortality experience of women is one of the socio-economic variables in this study to address the problem of ex-post rationalization. Furthermore, findings from the survey could suffer from a time-sequence challenge in determining factors associated with fertility gap, hence, it is difficult to draw clear causality conclusions. Despite these limitations, this study is one of the few to examine the trend and predictors of underachieved and achieved fertility among women with completed fertility in the context of sub-Saharan Africa. The findings of the study based on large data sets representing the country can be generalized. The use of multinomial logistic regression analysis helped to understand the factors that predict the changing trend of underachieved and achieved fertility in Ghana. Furthermore, the findings of this study provide policy makers with a clearer understanding of factors that need to be considered in programmes and interventions to further reduce fertility.

\section{Conclusion}

This paper aimed at understanding the factors that persistently predict underachieved and achieved fertility over the three rounds of the GDHS. Three factors emerged as consistently influencing underachieved and achieved fertility over the 10-year period: child loss experience, ethnicity and couple's fertility preference. The findings highlighted that child loss experience tend to influence achieved or underachieved negatively. The study also underscores the critical role played by men in shaping fertility gap of women. Finally, fertility gap of an ethnic group could be explained by socio-demographic characteristics of the ethnic group. The study is important for theoretical understanding of fertility gap. In particular, the study brings new insights into the discussion on fertility gap regarding ethnic group differences among women in sub-Saharan Africa.

Considering the role played by men in women's ability to achieve their preferred family size, efforts to reduce fertility in sub-Saharan Africa must consider how to reduce men's higher fertility preference. The study, therefore, recommend that programmes to reduce fertility in sub-Saharan Africa must consider the significant role played by men in fertility decisions. In addition, researchers must consider placing equal emphasis on the 
fertility behaviour of men in any analysis of fertility among women to be able to properly inform relevant policy interventions towards achieving further fertility reduction in Ghana and the rest of sub-Saharan Africa. More importantly, programmes towards reducing infant and child mortality in Ghana and elsewhere in sub-Saharan Africa need critical consideration if the fertility gap between fertility preference and actual fertility is to be bridged as part of efforts towards achieving further fertility decline.

\section{Abbreviations}

DHS: Demographic and Health Survey; GDHS: Ghana Demographic and Health Survey; GMHS: Ghana Maternal Health Survey; SDG: Sustainable Development Goal; SSA: Sub-Saharan Africa.

\section{Acknowledgements}

The authors would like to thank Measure DHS and the Ghana Statistical Service for granting them access to the data used in the analysis in this study.

\section{Authors' contributions}

All the authors are responsible and cooperated for the development of the paper. IY is responsible for data preparation and writing the original draft of the paper. SOK and FF-A are responsible for reviewing and editing the entire paper. All authors declare that they read and approved the final manuscript.

\section{Funding}

The authors received no specific funding for this work.

\section{Availability of data and materials}

The data sets generated and/or analyzed during the current study are available in the MEASURE DHS database at repository; http://dhsprogram.com/data/available-datasets.cfm.

\section{Declarations}

\section{Competing interests}

The authors have declared that they have no competing interests.

\section{Author details}

${ }^{1}$ Institute of Work, Employment and Society, University of Professional Studies, Legon, P.O. Box LG 149, Accra, Ghana.

${ }^{2}$ Regional Institute for Population Studies, University of Ghana, Legon, Accra, Ghana.

Received: 29 April 2021 Accepted: 30 September 2021

Published online: 19 October 2021

\section{References}

Adanu, R. M., Seffah, J., Anarfi, J. K., Lince, N., \& Blanchard, K. (2012). Sexual and reproductive health in Accra, Ghana. Ghana Medical Journal, 46(2), 58-65.

Agyei-Mensah, S. (2006). Fertility transition in Ghana: looking back and looking forward. Population, Space and Place, 12(6), $461-477$.

Ahinkorah, B. O., Seidu, A. A., Armah-Ansah, E. K., Budu, E., Ameyaw, E. K., Agbaglo, E., \& Yaya, S. (2020). Drivers of desire for more children among childbearing women in sub-Saharan Africa: implications for fertility control. BMC Pregnancy and Childbirth, 20(1), 1-11. https://doi.org/10.1186/s12884-020-03470-1

Akonor, N. O., \& Biney, A. A. E. (2021). Ethnicity and fertility desires in Ghana. J Pop Research, 38, 283-306. https://doi.org/ $10.1007 / \mathrm{s} 12546-021-09266-0$

Amu, H., \& Sekyi, D. K. (2018). Effects of spatial location and household wealth on the utilisation of skilled birth attendants at delivery among women in rural Ghana. Ghana Journal of Geography, 10(1), 58-77. https://doi.org/10.4314/gjg. v10i1.4

Aziato, L. (2016). The dynamic of female education from the basic to the tertiary levels in Ghana: challenges and reflections. The Social Work Practitioner-Researcher, 28(3), 330-343. https://doi.org/10.25159/2415-5829/1843

Bankole, A. (1995). Desired fertility and fertility behaviour among the Yoruba of Nigeria: a study of couple preferences and subsequent fertility. Population Studies, 49(2), 317-328. https://doi.org/10.1080/0032472031000148536

Bongaarts, J. (2017). Africa's unique fertility transition. Population and Development Review, 43, 39-58.

Bongaarts, J., \& Casterline, J. (2012). Fertility transition: is sub-Saharan Africa different? Population and Development Review, 38, 153-168. https://doi.org/10.1111/j.1728-4457.2013.00557.x

Caldwell, J., \& Caldwell, P. (1987). The cultural context of high fertility in sub-Saharan Africa. Population and Development Review, 13(3), 409-437.

Canning, D., Günther, I., Linnemayr, S., \& Bloom, D. (2013). Fertility choice, mortality expectations, and interdependent preferences-an empirical analysis. European Economic Review, 63, 273-289. https://doi.org/10.1016/j.euroecorev. 2013.07.005 
Casterline, J. B. (2017). Prospects for fertility decline in Africa. Population and Development Review, 43, 3-18. https://doi. org/10.1111/padr.12055

Casterline, J. B., \& Han, S. (2017). Unrealized fertility: fertility desires at the end of the reproductive career. Demographic Research, 36(14), 427-454. https://doi.org/10.4054/DemRes.2017.36.14

Channon, M. D., \& Harper, S. (2019). Educational differentials in the realisation of fertility intentions: is sub-Saharan Africa different. PLOS ONE, 14(7), e0219736.

Cleland, J., Machiyama, K., \& Casterline, J. B. (2020). Fertility preferences and subsequent childbearing in Africa and Asia: a synthesis of evidence from longitudinal studies in 28 populations. Population Studies, 74(1), 1-21. https://doi.org/10. 1080/00324728.2019.1672880

de Carvalho, A., Wong, L., \& Miranda-Ribeiro, P. (2016). Discrepant fertility in Brazil: an analysis of women who have fewer children than desired (1996 and 2006). Revista Latinoamericana De Poblacion, 10(18), 83-106.

DeRose, L. F., \& Ezeh, A. C. (2005). Men's influence on the onset and progress of fertility decline in Ghana, 1988-98. Population Studies, 59(2), 197-210. https://doi.org/10.1080/00324720500099496

Dodoo, F.N.-A. (1994). Relative spousal status and child health in sub-Saharan Africa: the case of Ghana. The Sociological Quarterly, 35(3), 507-519. https://doi.org/10.1111/j.1533-8525.1994.tb01742.x

Dodoo, F. N., \& Landewijk, P.V. (1996). Men, women, and the fertility question in Sub-Saharan Africa: an example from Ghana. African Studies Review, 39(3), 29-41.

Dreze, J., \& Murthi, M. (2001). Fertility, education, and development: evidence from India. Population and Development Review, 27(1), 33-63.

Feyisetan, B., \& Casterline, J. B. (2000). Fertility preferences and contraceptive change in developing countries. Source: International Family Planning Perspectives, 26(3), 100-109. https://doi.org/10.2307/2648298

Ghana demographic and health survey 1998. (1999). Ghana Statistical Service (GSS) \& Macro International Inc. In Calverton, Maryland: Vol. Calverton

Ghana demographic and health survery 2014. (2015). Ghana Statistical Service (GSS), Ghana Health Service (GHS), ICF International. In Rockville, https://doi.org/10.1007/b138909

Govindasamy, P., \& DaVanzo, J. (1992). Ethnicity and fertility differentials in Peninsular Malaysia: do policies matter? Population and Development Review, 18(2), 243-267.

Günther, I., \& Harttgen, K. (2016). Desired fertility and number of children born across time and space. Demography, 53, 55-83. https://doi.org/10.1007/s13524-015-0451-9

Gyimah, S. O. (2002a). Ethnicity and infant mortality in sub-Saharan Africa: the case of Ghana. PSC Discussion Papers Series, 16(10), 1-31.

Gyimah, S. O. (2002b). Fertility response to childhood mortality in sub- Saharan with emphasis on Ghana and Kenya. PSC Discussion Papers Series, 16(2), 1-25.

Gyimah, S. O., \& Fernando, R. (2004). Intentional replacement of dead children in sub-Saharan Africa: evidence from Ghana and Kenya. Canadian Studies in Population, 31(1), 33. https://doi.org/10.25336/p64g7q

Hinson, L. (2015). Fertility preferences in the relationship context in Ghana. John Hopkins University Bloomberg School of Public Health (Doctor of Philosopy Thesis).

Ibisomi, L., Gyimah, S., Muindi, K., \& Adjei, J. (2011). Ideal versus actual: the contradiction in number of children born to Nigerian women. Journal of Biosocial Science, 43(2), 233-245. https://doi.org/10.1017/S0021932010000684

Isiugo-Abanihe, U. C. (1994). Reproductive motivation and family-size preferences among Nigerian men. Studies in Family Planning, 25(3), 149-161. https://doi.org/10.2307/2137941

Jayachandran, S., \& Kuziemko, I. (2011). Why do mothers breastfeed girls less than boys? Evidence and Implications for Child Health in India. The Quarterly Journal of Economics, 126(3), 1485-1538. https://doi.org/10.1093/qje/qjr029. Advance

Jones, G. W. (1990). Fertility transitions among Malay populations of southeast Asia: puzzles of interpretation. Population and Development Review, 16(3), 507-537.

Kayode, G. A., Grobbee, D. E., Koduah, A., Amoakoh-Coleman, M., Agyepong, I. A., Ansah, E., van Dijk, H., \& KlipsteinGrobusch, K. (2016). Temporal trends in childhood mortality in Ghana: impacts and challenges of health policies and programs. Global Health Action, 9(1), 1-11. https://doi.org/10.3402/gha.v9.31907

Kebede, E., Goujon, A., \& Lutz, W. (2019). Stalls in Africa's fertility decline partly result from disruptions in female education. Proceedings of the National Academy of Sciences of the United States of America, 116(8), 2891-2896. https://doi.org/10. 1073/pnas. 1717288116

Kebede, E., Striessnig, E., \& Goujon, A. (2021). The relative importance of women's education on fertility desires in subSaharan Africa: a multilevel analysis. Population Studies. https://doi.org/10.1080/00324728.2021.1892170

Kidayi, P. L., Msuya, S., Todd, J., Mtuya, C. C., Mtuy, T., \& Mahande, M. J. (2015). Determinants of modern contraceptive use among women of reproductive age in Tanzania: evidence from Tanzania demographic and health survey data. Advances in Sexual Medicine, 5, 43-52. https://doi.org/10.4236/asm.2015.53006

Kodzi, I. A., Johnson, D. R., \& Casterline, J. B. (2010). Examining the predictive value of fertility preferences among Ghanaian women. Demographic Research, 22(30), 965-984. https://doi.org/10.4054/DemRes.2010.22.30

Kodzi, I. A., Johnson, D. R., \& Casterline, J. (2012). To have or not to have another child: life cycle, health and cost considerations of Ghanaian women. Social Science and Medicine, 74(7), 255-269. https://doi.org/10.1016/j.trsl.2014.08.005.The

Liefbroer, A. C. (2009). Changes in family size intentions across young adulthood: a life-course perspective. European Journal of Population/revue Européenne De Démographie, 25(4), 363-386.

Mason, K. O. (1997). Explaining fertility transitions. Demography, 34(4), 443-454.

Mbacké, C. (2017). The persistence of high fertility in sub-Saharan Africa: a comment. Population and Development Review, 43, 330-337. https://doi.org/10.1111/padr.12052

Morgan, S. P., \& Rackin, H. M. (2010). The correspondence between fertility intentions and behavior in the United States. Population and Development Review, 36(1), 91-118. https://doi.org/10.1111/j.1728-4457.2010.00319.x

Muhoza, D. N., Broekhuis, A., \& Hooimeijer, P. (2014). Variations in desired family size and excess fertility in East Africa. International Journal of Population Research, 2014(1), 1-11. https://doi.org/10.1155/2014/486079 
Nitsche, N., \& Hayford, S. R. (2020). Preferences, partners, and parenthood: linking early fertility desires, marriage timing, and achieved fertility. Demography, 57, 1975-2001. https://doi.org/10.1007/s13524-020-00927-y

Odusina, E. K., Ayotunde, T., Kunnuji, M., Ononokpono, D. N., Bishwajit, G., Yaya, S., \& Yaya, S. (2020). Fertility preferences among couples in Nigeria: a cross sectional study. Reproductive Health, 17(1), 1-9. https://doi.org/10.1186/ s12978-020-00940-9

Palloni, A., \& Rafalimanana, H. (1997). The effects of infant mortality on fertility revisited: some new evidence. Center for Demography and Ecology Working Paper, 96(27).

Philipov, D., \& Bernardi, L. (2011). Concepts and operationalisation of reproductive decisions: implementation in Austria Germany and Switzerland. Comparative Population Studies, 36(2-3), 531-572. https://doi.org/10.4232/10. CPOS-2011-14en

Poppel, F. V., Reher, D. S., Sanz-Gimeno, A., Sanchez-Dominguez, M., \& Beekink, E. (2012). Mortality decline and reproductive change during the Dutch demographic transition: revisiting a traditional debate with new data. Demographic Research, 27, 299-338. https://doi.org/10.4054/DemRes.2012.27.11

Reher, D. S., Sandström, G., Sanz-Gimeno, A., \& van Poppel, F. W. A. (2017). Agency in fertility decisions in western Europe during the demographic transition: a comparative perspective. Demography, 54(1), 3-22. https://doi.org/10.1007/ s13524-016-0536-0

Rosero-Bixby, L., \& Casterline, J. B. (1993). Modelling diffusion effects in fertility transition. Population Studies, 47(1), $147-167$.

Schoumaker, B. (2019). Stalls in fertility transitions in sub-Saharan Africa: revisiting the evidence. Studies in Family Planning, 50(3), 257-278. https://doi.org/10.1111/sifp.12098

Trinitapoli, J., \& Yeatman, S. (2018). The flexibility of fertility preferences in a context of uncertainty. Population and Development Review, 44(1), 87.

Van de Poel, E., O'Donnell, O., \& Van Doorslaer, E. (2009). What explains the rural-urban gap in infant mortality: household or community characteristics. Demography, 46(4), 827-850. https://doi.org/10.1353/dem.0.0074

Van Lith, L. M., Yahner, M., \& Bakamjian, L. (2013). Women's growing desire to limit births in sub-Saharan Africa: meeting the challenge. Global Health: Science and Practice, 1(1), 97-107. https://doi.org/10.9745/ghsp-d-12-00036

Voas, D. (2003). Conflicting preferences: a reason fertility tends to be too high or too low. Population and Development Review, 29(4), 627-646.

Wencak, J. (2013). Excess fertility and infant mortality in Sub-Saharan Africa. MA Thesis. Graduate College of Bowling Green, State University

Wulifan, J. K., Mazalale, J., Jahn, A., Hien, H., Ilboudo, P. C., Meda, N., Robyn, P. J., Hamadou, S., Haidara, O., \& Allegri, M. D. (2017). Factors associated with contraceptive use among women of reproductive age in rural districts of Burkina Faso. Journal of Health Care for the Poor and Underserved, 28(1), 228-247. https://doi.org/10.1353/hpu.2017.0019

Yeboah, I., Kwankye, S. O., \& Frempong-Ainguah, F. (2021). Predictors of underachieved and overachieved fertility among women with completed fertility in Ghana. PLOS ONE, 16(6), e0250881.

\section{Publisher's Note}

Springer Nature remains neutral with regard to jurisdictional claims in published maps and institutional affiliations.

\section{Submit your manuscript to a SpringerOpen ${ }^{\circ}$ journal and benefit from:}

- Convenient online submission

- Rigorous peer review

- Open access: articles freely available online

High visibility within the field

- Retaining the copyright to your article

Submit your next manuscript at $\boldsymbol{\nabla}$ springeropen.com 